\title{
The Research Status and Prospects of Peony Diseases
}

\author{
Yuna Wang ${ }^{1}$ \\ ${ }^{1}$ Department of Life Science, Luoyang Normal University, Luoyang, Henan Province, China
}

Keywords: Peony, disease, presents situation and prospect, prevention and control technology

\begin{abstract}
Peony is one of the traditional famous flowers in China, as the king of flowers, there are "very beautiful" "flower in the king" said. Peony and the kinds of peony diseases are introduced in this paper, the present situation of the prevention and control technology and the problems existing in the current research on peony diseases are summarized. Focus on these problems, puts forward prospect of peony diseases prevention and control.
\end{abstract}

\section{Introduction}

Peony, elegant, is a rare flower of China. In China, it has a long history of cultivation; the cultivation scale is huge, formed in central China, northwest, south, and southwest of the big four peony species group [1]. In terms of commodity production, formed in Heze, Luoyang and other traditional origin is given priority to the cultivation of production center. Is the world's largest peony production base in China, its cultivation area of $3150 \mathrm{~m}^{2}$, seedlings sales each year more than 200 plants, its exports seedlings and potted flower quantity are increasing year by year; Followed by Luoyang, Luoyang peony has a long history and wide variety, spend big color bright, after years of development, the existing varieties of peony in more than 600, more than 5000 plants, plant area of nearly $700 \mathrm{~m}^{2}$, planting base (park), at present, in Luoyang has been formed to watch the seedlings, flowers, and tourism as the center of peony industrialization pattern [1]; The 3rd is Lanzhou in Gansu province and its surrounding areas, to plant drought resistance, cold resistance and resistance to poor purple peony, give priority to with purple peony seed sales and exports.

Since the ancient times the peony, with its solemn gorgeous and elegant enshrouded a symbol of "prosperity and good fortune," domestic peony cultivation area of the rapidly expanding and more varieties,. Domestic scholars in the process of biological characteristics, pathogen infection, disease prevention and control and have done a lot of work [1]. At present, the domestic peony disease there is an upward trend in the lupus disease; peony lupus disease has become one of the most serious diseases to harm. Pathogen infection after the peony, peony design and color is caused by a recession, impaired growth and less Dan leather quality is poor, causing the farmers economic losses, the outbreak of the disease and epidemic seriously restrict the development of peony industrialization in our country [1]. This research through the naming of peony red spot disease, pathology, pathogenesis regularity, disease investigation and agents in the field and indoor conditions control effects such as summary, provide a reference for the peony red spot disease of comprehensive prevention and control.

\section{The peony diseases}

Peony common diseases are leaf spot (Cladosporiumpaeoniae), grey mould (Botrytiscinerea), rust (Conartitum flaccidium), since the southern blight (Sclerotiumvoifsii) and the purple stripes feather disease (Helicobasidium mompa), etc. Stem diseases on the harmfulness of the peony has the special early onset, the plant has no obvious change appearance, branch close to death, until the disease symptoms didn't show it. This kind of disease the peony stem withering sparse until all died [2]. The peony stem parts of the disease mainly include branch blight, gray mold, and anthracnose. Seedlings, old trees are infection, 15 years old, height nearly $2 \mathrm{~m}$ of the plants are not immune. 
Cladosporiumpaeoniae. Leaf spot and red spot disease, the disease mainly damage vane, also can infect stem, flower and corolla or fallen petal occur before, during, and after flowering, continue to stage the withered leaves. Pathogenic fungi of peony branch spore mould (Cladosporium paeoniae) belong to the imperfect phylum bacteria subphylum silk spore plexus spore mesh branch spore bacteria genera [2]. Pathogens to mycelium or conidium wintering in dead leaves or soil, wrong to help spread starts early summer, autumn, harm is serious, high temperature and high humidity, illumination is insufficient, poor ventilation, continuous cropping, etc are conducive to disease occurs.

Botrytiscinerea. Grey mould of the disease harm seedlings, leaf, stem and flower etc. Seedling stem base killed when produce irregular disease spot, brownish, sag, decay, lodging, plant disease department appear dark brown mould; Blade suborbicular spots after suffer, maroon or dark brown, with irregular round lines. Pathogenic fungi for Botrytis cindered Peers or agonies Oud Sclerotium produce conidiophores germination, spores by wind and rain infection, peony continuing to infect the whole growth period [3].

Conartitum flaccidium. Peony by rust after infection leaves appear small yellowish brown spots, soon swelled into orange blister, blister material later burst out orange yellow powder, namely summer spores [1]. Pathogenic fungi are Conartium flaccidiumWint.

Sclerotiumvoifsii. Major hazard root neck this disease, early onset of root collar surface white mycelium, skin organization gradually sinking, and grow a white mycelium, then grow sclerotium. Pathogenic fungi are Sclerotium rolfsii Sace [2].

Helicobasidium mompa. Risk more than in the root, neck and root killed parts covered with cotton wool purple hyphae [2]. Pathogenic bacteria are Helicobasidium mompa Fanaka.

The peony branch blight. The shoot blight pathogen is not entirely sure. According to the author field investigation and information research, preliminary thought mainly caused by Leptosphaeria fungi.

Peony anthrax. The peony anthracnose caused by fungus gloeosporiumsp. The bacteria can also harm the peony leaf.

Powdery mildew. Powdery mildew is one of the more common in peony diseases, is the harm on the surface of a layer of white powdery mildew layer, is the disease of conidium. Pathogens to mycelium wintering in the sleeping bud, at conidium, infection again [3]. Small and less serious when flowers, leaves wither, can't even flower, whole plant death.

Lupus disease. Peony lupus disease occur widely, incidence of a disease in different peony cultivars varies, most of the peony incidence of around 50\% in June, 8 - September rates above 90\%. The disease mainly damage green stems and leaves, also can infect petioles and leaves. Leaf disease, early onset chin, appears on the back of the green needles and expanded into $10 \sim 30 \mathrm{~mm}$ after $30 \mathrm{~d}$ disease spot [4]. Disease spot suborbicular, amaranth, connected to some disease spot piece, most of the disease spot had obvious concentric round lines, and the disease spot withered. Late onset, in the humid climate conditions, back in beige mildew, this is a pathogen of conidium terrier and conidium. Stem suffer long dark purple dots, after some bumps, disease spot expanding slowly, late disease spot diameter is only $3 \sim 5 \mathrm{~mm}$ long; Disease spot between crack and subsidence, serious when connected to disease spot piece, damp disease can also cause mildew layer, often leads to twigs to die. In the stem was never observed on fruiting body. Several years of serious plant growing short, mostly withered, can blossom, all die, even lose the ornamental value?

\section{Peony diseases research existing problems and development direction}

The peony diseases lack of continuous investigation. As domestic peony varieties breeding and introduction of new varieties of abroad, the diseases will occur, the corresponding transformation, potted peony, winter greenhouse rush flowers peony disease needs to be ongoing investigation, in order to make clear disease type and new type of such defects.

Pathogenic species of uncertainty. The data reported, peony grape grey mould by peony spore and grey spore caused kinds of pathogens, but only when the author in the separation of grey mould of pathogen separation to grey grapes spore, not separation to the peony grape spore, the specific reason 
need further verification [3]. In addition, spot disease, at the column spore leaf spot, melasma, and pathogenic species at present has not yet been determined.

New disease etiology is unknown. Peony produces in the process of flower bud differentiation in recent years a large number of blind shoots, Japan to the top of the peony flower bud flowering stem tip is not nematode damage caused by, domestic peony is blind bud stem tip nematodes harm or other diseases, to study appraisal, and make effective prevention and treatment [4]. In addition to rush flowers peony is worth studying a large number of frozen grey phenomenon in, whether physiological disease to do further research.

The determination of peony virus disease still needs to study. Books and articles about the peony cultivation, reported the peony Mosaic virus disease. The flowers and plants in Luoyang company will have a mosaic symptoms of plants do electron microscopy examination to the Nanjing forestry university, did not detect the virus, still need to do further research to determine the peony Mosaic virus disease symptoms and poison. S.L. Chang thinks green peony pea green to bake with representative varieties may be caused by a virus, also did not identify, need to do further research to determine whether associated with the infection of the virus [5].

The peony diseases physiological research is not thorough. About how peony pathogen invasion of peony of, or intrusion into, within the plant after the disease process, and the peony plant their own defense reaction and physiological and metabolic changes, these are the unknown, needs to be studied further.

The lack of a novel and effective prevention measures. Peony diseases prevention and control of stays on the traditional method of prevention and cure, some varieties are resistant, peony diseases to make use of chemicals has been difficult to effective prevention and control, has yet to implement safety, environmental protection, economic and effective new method for comprehensive control of peony diseases.

\section{The research prospect of peony diseases}

Environmental conditions affecting the peony disease epidemic and pathogens invasion condition investigation and research, understanding the law of the peony diseases, understanding the peony defense reaction caused by pathogens infection after their own. These studies can provide theoretical basis for disease prevention and control of peony, the peony industry, health, sustainable development of the science.

Research on peony diseases materials are mainly belt Heze peony, and Luoyang peony diseases carried out investigation and study, and analyzed the peony diseases and disease onset and symptoms and disease epidemic law of development. Monographs on the peony, only a small amount of content involves the peony diseases in other hard to find relevant information. In foreign countries, Japan and France peony variety, cultivation area is large, but there are few research on peony diseases data. China's research on peony diseases mainly focus on several kinds of diseases, such as, peony, peony, peony root rot disease lupus disease nematode, etc [5]. The introduction of new varieties, forcing the peony and potted peony blooms, peony will cause new diseases. China's census of the diseases are not very comprehensive, therefore, it is necessary to research on peony diseases systematically, understand the kinds of peony diseases, diseases of law of development, for the peony of effective prevention and control of diseases to provide theoretical basis for production practice.

Root rot. Root rot is one of the important problems of Dan peony. After early risk in the roots, yellowish-brown, turning black, disease spot sag, sizes and can be up to the marrow, blackening the lesion site, the roots can be full or partial murder, sick old plant root rot, the new root is not born, some leaves yellow, the withering on the ground [6]. Branches thin, later, even the whole plant death. The influence of continuous cropping diseases occurrence and harm is very obvious. General soil heavy, low-lying, not easy drainage block heavy disease, Dan root by the underground pests (such as mole, grubs, etc.) harm plants was seriously ill.

Root rot pathogen hyphae and conidium wintering in diseased root. As the ground temperature in early march, pathogenic bacteria can start activity, through the wound and natural orifice into roots, to come on stage, late October bacteria stop impregnation [6]. Pathogenic bacteria with the close water 
transmission, or spread over a long distance with the nursery stock dispatching. The incubation period is 15 to 20 days.

To find the strain of dug deep and in the hole and some lime soil disinfection or sulfur powder combined with sunshine. Chemical control can use at the arsenic, corruption will cure or more f wet table powder to root, control effect can be achieved 84 - more than 90\%.

Mould. Peony mould is a kind of common, harm of severe disease, especially in humid rainy season. The onset of serious when a leaf dry rot, young stem and leaf. Grey mould of major hazard of blade, especially lower leaves vulnerable to infection. Early onset, appear on the blade suborbicular or irregular shape with particular disease spot, develops in leaf and leaf margin [7]. Late disease spot the diameter is more than $1 \mathrm{~cm}$ in more. Disease spot a maroon to beige, brown, sometimes produce wheel grain. Under the condition of high humidity, produce a gray mold disease department. Petiole and stem morbidity, with particular shape green long streak, after brown sag, soft rot disease department, lead to broken plant. Petals disease, brown rot, produce grey mildew layer. Available mildothane or carbendazim is fluid control.

Leaf spot. Leaf spot is also called round spot, Dan peony is one of common leaf diseases. The early onset of victim's vane of brown is dark brown round disease spot. Disease spot with concentric round lines, size, diameter of $2 \sim 10 \mathrm{~mm}$. Late disease, the disease spot on black mildew layer; Adjacent disease spot can be healing into irregular spots [7]. The onset of serious blade is full of disease spot of water. Peony disease spots appear on the tender stems and petioles in late march. By early April new leaves just can see needles soon disease spot, connected into disease spot gradually expanded, after come on stage. In the early of November, pathogen is in the winter period. Choice of carbendazim and mildothane, mixed with foliage dressing for prevention and control.

Damping off. Damping off more appeared in the new seedling plots. Pathogen for dry silk nuclear bacteria, bacteria from the soil surface into Feng Dan peony seedling stem base. In base of seedlings after the first turn brown, dark brown, serious when a dark brown rot. ), and wilting, dying plants (occurred strain leaves yellow, but no lodging [8]. Bacteria can also infect shoot nearly wet leaves on the ground, lead to bacterial leaf blight, and quickly spread to the whole leaf and petiole, causing death rotten. Onset of plots available enemy sulfuric sodium (enemy eriksson), etc. .

Root knot nematodes. Peony is the roots of the knot nematode infection, nutrition on the root grow tumour, nodule formation, and long fibrous root nodule, long again on fibrous tumor, can be repeated many times, make nodule shows from dendritic, and seriously affect the phoenix Dan growth and flowering of peony. Usually root knot nematodes to female worm and eggs in phoenix peony root wintering, Dan peony second infection in early newborn root nutrition mainly is the second instar larvae overwintering eggs hatch [7]. Root knot nematodes by soil, water, tools, and seedling propagation are in spite of illness. Can use salix methyl isopropyl phosphorus or abamectin root treatment for prevention and control effect can be achieved by more than $85 \%$.

Peony varieties breeding technology has been very mature, but the main focus on design and color, after can also from the perspective of cultivating disease-resistant varieties, using not infected peony varieties as a parent, hybridization with other varieties, breeding disease-resistant varieties, in order to achieve the purpose of prevention and cure of diseases [8]. In addition, the biological fungicide can be used to resist disease resistance. All these aspects need to be further in-depth study.

Based on the peony leaf spot pathogens peony branch spore mould (Cladosporium paeoniae) as an example, introduces the bacteriostatic circle method, namely the bacteriostatic effect of bacteriostasis to ring size is a standard, bacillus screening for antagonism [8]. Is the most significant effect of bacillus strains, bacteriostatic circle diameter $5.68 \mathrm{~mm}$ and $5.97 \mathrm{~mm}$ respectively? Then through a series of evaluation test, including the colonies and the body characteristics test observation and physiological and biochemical characteristics, a comprehensive evaluation of the above test results, ultimately determine the inhibitory actions belong to Bacillus subtilis genera (Bacillus subtilis).

\section{Summary}

Along with the increase in peony varieties all over the country, the expansion of production area, disease problem increasingly prominent, seriously affected the normal growth and development of 
peony, seedlings quality and quality of flowering, reduces the peony ornamental effect, influence the industrialization development of peony. Deal with peony diseases, therefore, summarizes the research status, find out the existing problems, and according to these problems of research on peony diseases in the future put forward rational Suggestions, so as to provide theoretical basis for peony diseases prevention and control work, to promote the industrialization of peony.

Research on peony diseases in many aspects is not very deeply and thoroughly, need to invest more manpower and material resources to complete each work, to improve the quality of peony products to improve the viewing effect, reduce the economic loss, to speed up the pace of the industrialization development of peony.

\section{Acknowledgement}

The Education Department Project of Henan Province (14A210013). The Science and Technology Department Project of Henan Province(132102110104).

\section{References}

[1] L. J. Xue, Main diseases prevention and control of forestry practical technology in Heze peony, 2005, vol. 4, pp. 26-28.

[2] S. J. Yu and Z. S. Zhang, The integrated control of tree peony and herbaceous peony main diseases in Beijing, Journal of Beijing forestry University, 2003, vol. 2, pp. 103-108.

[3] X. M. Lin, Plant diseases and insect pests of peony species research, inspection and quarantine science, 2002, vol. 6, pp. 4446.

[4] Z. Y. Zhang, Peony leaf spot preliminary observation and prevention, Chinese garden, 2011, vol. 7 , pp. 53-56.

[5] S.L. Chang, Peony lupus disease occurrence regularity and control technology research, Shandong forestry science and technology, 2008, vol. 2, pp. 37-39.

[6] Y. P. Chi, Peony lupus disease pathogen research, Shandong forestry science and technology, 2001, vol. 1, pp. 21-23.

[7] Y. Zh. Wu, Peony lupus disease pathogenesis regularity of observation, Forest diseases and pests in China, 2004, vol. 5, pp. 6 -10.

[8] Y. T. Hu, Peony of main diseases and prevention research, The western forestry science, 2006, vol. 4, pp. 40-44. 